\title{
High mammographic density in women of Ashkenazi Jewish descent
}

\author{
Jennifer L Caswell ${ }^{1}$, Karla Kerlikowske ${ }^{2}$, John A Shepherd ${ }^{3}$, Steven R Cummings ${ }^{4}$, Donglei Hu${ }^{1}$, Scott Huntsman ${ }^{1}$ \\ and Elad Ziv ${ }^{1 *}$
}

\begin{abstract}
Introduction: Percent mammographic density (PMD) adjusted for age and body mass index is one of the strongest risk factors for breast cancer and is known to be approximately $60 \%$ heritable. Here we report a finding of an association between genetic ancestry and adjusted PMD.
\end{abstract}

Methods: We selected self-identified Caucasian women in the California Pacific Medical Center Research Institute Cohort whose screening mammograms placed them in the top or bottom quintiles of age-adjusted and body mass index-adjusted PMD. Our final dataset included 474 women with the highest adjusted PMD and 469 with the lowest genotyped on the Illumina $1 \mathrm{M}$ platform. Principal component analysis (PCA) and identity-by-descent analyses allowed us to infer the women's genetic ancestry and correlate it with adjusted PMD.

Results: Women of Ashkenazi Jewish ancestry, as defined by the first principal component of PCA and identity-bydescent analyses, represented approximately $15 \%$ of the sample. Ashkenazi Jewish ancestry, defined by the first principal component of PCA, was associated with higher adjusted PMD $(P=0.004)$. Using multivariate regression to adjust for epidemiologic factors associated with PMD, including age at parity and use of postmenopausal hormone therapy, did not attenuate the association.

Conclusions: Women of Ashkenazi Jewish ancestry, based on genetic analysis, are more likely to have high ageadjusted and body mass index-adjusted PMD. Ashkenazi Jews may have a unique set of genetic variants or environmental risk factors that increase mammographic density.

\section{Introduction}

Percent mammographic density (PMD) is the proportion of radiographically dense breast tissue as a fraction of the entire breast and can be calculated from a two-dimensional mammogram image [1-3] or as a fraction of the entire volume of the breast [4-13]. PMD is a strong risk factor for breast cancer; women of the same age and body mass index (BMI) in the upper quartile of PMD have a fourfold to sixfold higher risk of breast cancer than women in the lower quartile [1,3,14-20].

Many of the risk factors for high PMD are also risk factors for breast cancer, including late parity and use of postmenopausal hormone therapy with estrogen and progestin $[3,21]$. However, reproductive and hormonal

\footnotetext{
* Correspondence: elad.ziv@ucsf.edu

'Department of Medicine, Division of General Internal Medicine, Institute for Human Genetics, Helen Diller Family Comprehensive Cancer Center, University of California, $14503^{\text {rd }}$ Street, San Francisco, CA 94143, USA Full list of author information is available at the end of the article
}

factors account for a small proportion of the variation in PMD [21], and PMD remains a risk factor for breast cancer when adjusting for these factors [22,23]. Approximately $60 \%$ of the variance in PMD is heritable [24-27] and some genetic variants that are associated with breast cancer risk are also associated with increased PMD [28]. Both linkage and genome-wide association studies have been used to search for genetic determinants of PMD [29-33]. To date, the majority of heritability remains unexplained; for example, a recent genome-wide association study found SNP variants accounting for only $0.5 \%$ of the variance in PMD [30].

Identifying an ethnic population with higher PMD may have implications for breast cancer risk in that population and could open new avenues to map genes for this trait. We genotyped US Caucasian women at the extremes of adjusted PMD and evaluated the association between genetic ancestry and adjusted PMD,
C Biomed Central

다 2013 Caswell et al.; licensee BioMed Central Ltd. This is an open access article distributed under the terms of the Creative Commons Attribution License (http://creativecommons.org/licenses/by/2.0), which permits unrestricted use, distribution, and reproduction in any medium, provided the original work is properly cited. 
uncovering a previously unknown association between Ashkenazi Jewish ancestry and adjusted PMD.

\section{Methods \\ Study sample}

Study subjects were selected from 4,511 women enrolled in the California Pacific Medical Center Breast Health Cohort who underwent screening mammography between January 2004 and April 2006 and consented to provide blood specimens between July 2004 and June 2007. The California Pacific Medical Center Breast Health Cohort is linked to the San Francisco Mammography Registry, part of the NCI Breast Cancer Surveillance Consortium that collects demographic and risk factor data on women receiving mammography.

The questionnaire includes information on age, race, height, weight, parity history, postmenopausal hormone therapy use, personal history of breast cancer, and family history of breast cancer (in mother, sister, or daughter). The questionnaire allows the following categories for race/ ethnicity: White/Caucasian, Black/African American, Hispanic/Latina, American Indian, Chinese, Japanese, Filipina, Vietnamese, Other Asian and Other; it did not include Ashkenazi Jewish as a category. Only women who reported White/Caucasian race/ethnicity were included in this study. We excluded women who reported a personal history of breast cancer.

All participants gave informed consent to participate in the research. The study was approved by the University of California, San Francisco and the California Pacific Medical Center institutional review boards.

\section{Measurement of mammographic density}

PMD was calculated from craniocaudal digitized film mammograms using single X-ray absorptiometry (SXA), as described in [4]. In brief, the method makes two separate calculations: the total volumetric density and the total breast density. PMD is calculated as the quotient of total volumetric density and total breast volume. To calculate the total volumetric density, a calibrated phantom reference material is placed in the unused corner of the film mammogram. The phantom is composed of two materials, one the same density as fat and the other the same density as fibroglandular tissue. For each pixel of the mammogram, the percent density is calculated based on where that pixel falls on the gray scale from the low-density material to the high-density material. Total volumetric density is then calculated as the average of these values across all breast pixels. Total breast volume is calculated based on the distance between the X-ray source and detector and an algorithm that takes into account the tilt of the source/detector and the shape of the compressed breast.

This method has been shown to be highly reproducible [4], and to be at least as strongly associated with breast cancer risk as traditionally estimated PMD [5]. We used the average PMD of the right and left breasts. For women who only had a value for PMD on one side, we used the measurement from the side with data.

\section{Selection of women with high and low adjusted percent mammographic density}

We used age-adjusted and BMI-adjusted PMD to select participants for the genetic study. We square root-transformed PMD to make the data less skewed (Figure S1 in Additional File 1) and then used a linear regression model to calculate the association between age, BMI, and square root-transformed PMD. We used the residuals of this model as the adjusted PMD value for each woman. We selected 500 women with adjusted PMD in the highest quintile and 500 women with adjusted PMD in the lowest quintile for genotyping. Of these, we were able to identify 494 corresponding biospecimens from women in the top quintile and 489 biospecimens from women in the bottom quintile. All 1,000 women were linked to the California Cancer Registry by the San Francisco Mammography Registry annually since 2004 to confirm the women did not develop breast cancer after their screening examination.

\section{Genotyping}

The samples were genotyped on the Illumina $1 \mathrm{M}$ platform at the Center for Inherited Disease Research. A total of 40 samples were excluded from further analysis because they were unexpected duplicates of other samples $(n=7)$, they did not perform well in genotyping $(n=25)$, they did not cluster with European samples in principal component analysis (PCA) $(n=4)$ (Figure S2 in Additional File 1), they appeared in the dataset as both a high-density sample and a low-density sample $(n=1)$, they were found to be unexpected full siblings of other samples $(n=2)$, or they did not have an associated phenotype $(n=1)$ (Table S1 in Additional File 1), leaving 474 women with high adjusted PMD and 469 women with low adjusted PMD. Of the 1,043,142 SNPs genotyped, 45,933 were excluded from further analysis because they had no position information, they were mitochondrial or on the Y-chromosome, they were intensity-only or technical failures, or they had greater than $10 \%$ failed genotyping (Table S2 in Additional File 1).

\section{Statistical analyses}

We used $t$ tests and Wilcoxon rank-sum tests for continuous variables and used chi-square tests for categorical variables to determine whether there were significant differences between women with high adjusted PMD and women with low adjusted PMD for baseline characteristics and principal components (PCs).

We performed PCA using EIGENSTRAT [34]. To infer ancestry, we included publicly available $[35,36]$ genotype 
datasets from European and Middle Eastern samples with known ancestry: Italians $(n=14)$, Tuscans $(n=8)$, Basque $(n=24)$, French $(n=29)$, Orcadians $(n=16)$, Russians $(n=27)$, Adygei $(n=17)$, Sardinians $(n=28)$, Spanish $(n=12)$, Ashkenazi Jews $(n=21)$, and Palestinians $(n=$ 51). For the combined PCA analysis, we used a subset of 390,144 SNPs that were genotyped on both the Illumina 1 $\mathrm{M}$ platform and the other Illumina platforms used in the reference datasets. Changing the European and Middle Eastern groups did not substantially change the first principal component (PC1) (data not shown). For visualization of results in Figure 1, we selected the ancestry groups that most closely corresponded in the PC space to the Caucasian American women of our sample; these groups included the Italians, Tuscans, French, Orcadians, Russians, Adygei, Spanish, and Ashkenazi Jews.

We performed analysis of shared extended haplotypes (identity by descent (IBD)) using GERMLINE [37]. We defined a shared extended haplotype as being at least three centimorgans long, the default setting for GERMLINE. Prior to running GERMLINE we phased the genotype data and imputed missing genotypes using BEAGLE [38]. We calculated 95\% confidence intervals (CIs) of the mean shared IBD between groups, as well as $P$ values comparing two different means, using bootstrapping, resampling 1,000 times.

We performed multivariate logistic regression analysis on the outcome of high versus low adjusted PMD to assess whether the association between position on PC1 and adjusted PMD remained significant after adjusting for baseline characteristics using Stata software (version 10.0; Stata Corporation, 4905 Lakeway Dr., College Station, TX, 77845). For this analysis, we performed a linear transformation on PC1 in order to quantify the percent Ashkenazi Jewish ancestry on a scale of approximately 0 to 1 :

$$
\text { (Value of PC1 }-0.0309) /-0.1102
$$

After this transformation, a PC1 value of -0.0793 became 1.0, corresponding to the highest value of Ashkenazi Jewish ancestry in our sample, and a PC1 value of 0.1102 became 0.0 and was associated with the greatest

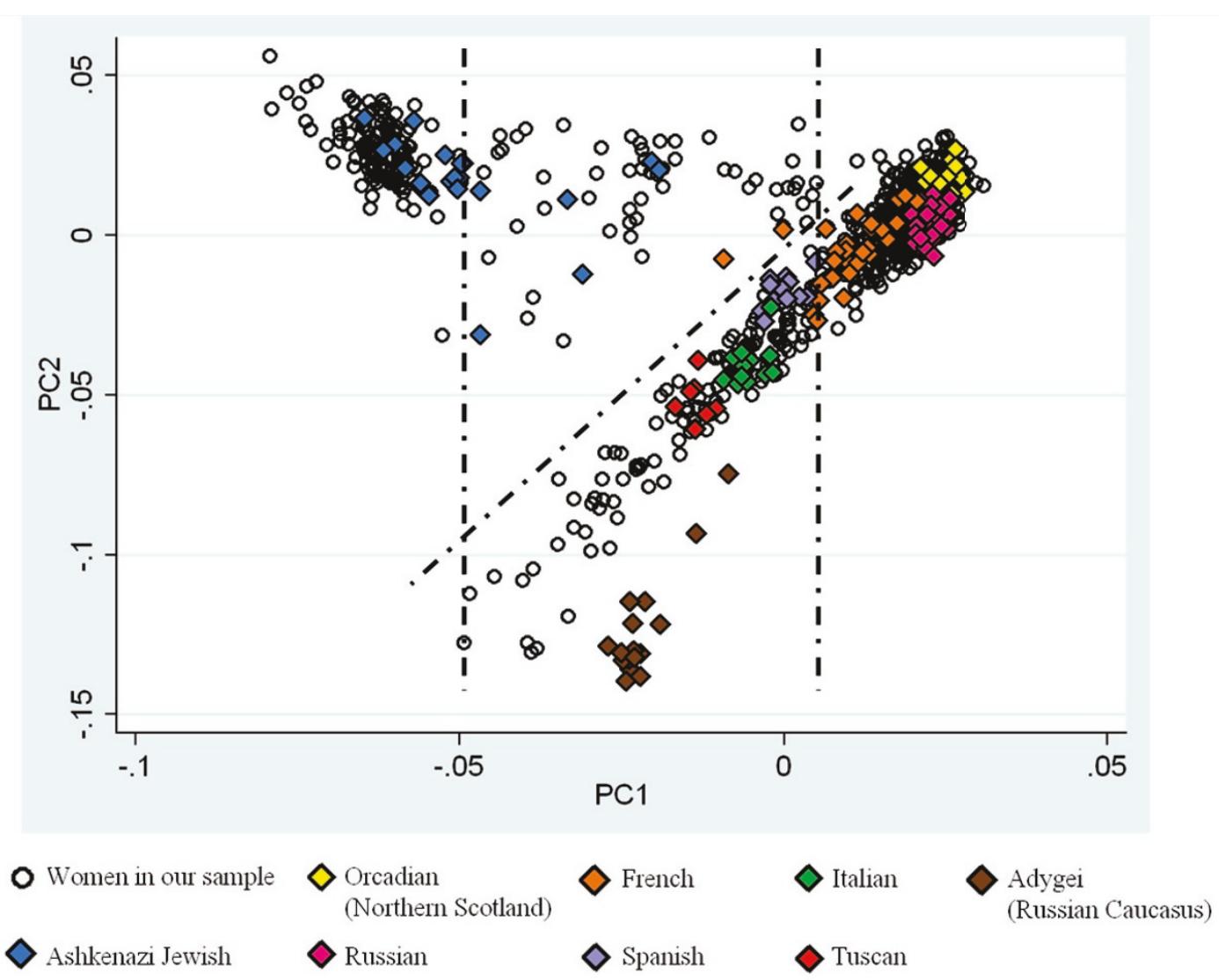

Figure 1 Principal component analysis of participants from our study and additional reference samples of known ancestry. The first principal component (PC1) separates people of Ashkenazi Jewish ancestry from other European groups. The vertical dotted lines separate the Ashkenazi Jewish and Northern European clusters from the middle group. The diagonal dotted line divides the probably mixed Ashkenazi-other European group (higher values on the second principal component (PC2)) from the Southern European group (lower values on PC2). 
distance along PC1 from individuals of Ashkenazi Jewish ancestry.

\section{Results}

Characteristics of women with high versus low adjusted percent mammographic density

The mammographic and epidemiologic characteristics of women with high versus low age-adjusted and BMIadjusted PMD are presented in Table 1. Unadjusted PMD and volume of mammographic density were significantly higher and total breast volume was lower in women with high adjusted PMD. Postmenopausal women were more likely to have lower adjusted PMD. Women with high adjusted PMD were more likely to have reported a family history of breast cancer.

BMI was significantly higher in women with high adjusted PMD by the Wilcoxon rank-sum test, but not by the $t$ test $(P=0.6)$. Our initial method of adjusting PMD for BMI assumed a linear relationship between BMI and PMD, while the relationship is in fact nonlinear, especially at higher BMI values (Figure S3 in Additional File 1). Women with higher BMI values were therefore overrepresented in the group with higher adjusted PMD.

\section{Identification of population substructure}

We performed PCA to determine the population substructure of our sample. First we performed PCA with populations of European, African, Asian, American, and Oceanian descent to verify the Caucasian ancestry of our sample population. Of the 951 women included in the initial analysis, four women appeared to have a possible admixture with Asian or African ancestry (Figure S2 in Additional File 1). To simplify the analysis, we excluded these women from additional analyses. Next, we performed the PCA again with only the population that clustered with European ancestry and incorporated publicly available genotyped samples from European and Middle Eastern populations of known ancestry (Figure 1). PC1 separated people of Ashkenazi Jewish ancestry from other European groups. Excluding the ancestral populations had no effect on PC1; the correlation of the component scores of $\mathrm{PC} 1$ when including versus excluding these samples of known ancestry was $r^{2}=1.0$. The second PC reflected Northern versus Southern European ancestry (Figure 1). When we excluded the ancestral populations, the component scores of the third PC were highly correlated with the component scores of the second PC with ancestral populations $\left(r^{2}=0.88\right)$.

Ashkenazi Jews have a significantly higher proportion of their genome that is IBD than other Caucasian populations $[39,40]$. We therefore performed analysis of IBD in our sample. We first defined two clusters in the PC space: a probable Northern European cluster (Group 1) with $\mathrm{PC} 1 \geq 0.005$ and a probable Ashkenazi Jewish cluster (Group 4) with PC1 $\leq-0.0495$ (Figure 1). Group 1 represented $65.7 \%$ of the total Caucasian sample and Group 4 represented $15.8 \%$. We compared the degree of IBD among pairs of women within each of the groups. The pairs of individuals in Group 4 averaged 23.2 centimorgans

Table 1 Characteristics of women with high adjusted percent mammographic density versus low adjusted percent mammographic density

\begin{tabular}{|c|c|c|c|}
\hline & High adjusted PMD & Low adjusted PMD & $P$ value \\
\hline Percent dense tissue by volume & $72.7(13.3)$ & $29.6(6.4)$ & $<10^{-3}$ \\
\hline Volume of dense breast tissue (ml) & $327.3(215.0)$ & $166.2(70.2)$ & $<10^{-3}$ \\
\hline Volume of the breast $(\mathrm{ml})$ & $479.1(354.6)$ & $576.5(242.9)$ & $<10^{-3}$ \\
\hline Age (years) & $52.4(9.7)$ & $51.7(7.8)$ & 0.9 \\
\hline Body mass index $\left(\mathrm{kg} / \mathrm{m}^{2}\right)$ & $24.1(6.5)$ & $23.9(3.1)$ & $<10^{-3}$ \\
\hline Age at first live birth & & & 0.1 \\
\hline$<30$ years & $96(20 \%)$ & $114(24 \%)$ & \\
\hline$\geq 30$ years or nulliparous & $378(80 \%)$ & $354(76 \%)$ & \\
\hline Unknown & 0 & 1 & \\
\hline \multicolumn{4}{|l|}{ Menopausal status } \\
\hline Premenopausal & $203(43.3 \%)$ & 159 (34.3\%) & \\
\hline Postmenopausal & $157(33.5 \%)$ & $183(39.4 \%)$ & $0.009^{*}$ \\
\hline Postmenopausal on hormone therapy & $71(15.1 \%)$ & $77(16.6 \%)$ & $0.7^{* *}$ \\
\hline Unknown & $38(8.1 \%)$ & $45(9.7 \%)$ & \\
\hline First-degree relative with breast cancer & & & 0.02 \\
\hline Yes & $114(24 \%)$ & $84(18 \%)$ & \\
\hline No & $366(76 \%)$ & 383 (82\%) & \\
\hline Unknown & 0 & 2 & \\
\hline
\end{tabular}

Data presented as mean (standard deviation) or $n$ (\%). PMD, percent mammographic density. Chi-squared $P$ values calculated excluding the samples with unknown values. ${ }^{*} P$ value for comparison with premenopausal women. ${ }^{* *} P$ value for comparison with postmenopausal women not taking hormone therapy. 
of shared haplotypes compared with 6.0 centimorgans in the pairs from Group 1 (bootstrap $P<10^{-3}$ ), consistent with the hypothesis that Group 4 represented women of Ashkenazi Jewish descent.

\section{Ashkenazi Jewish ancestry is associated with high adjusted percent mammographic density}

We examined the association between PCs from the genetic ancestry analysis and adjusted PMD. We identified a significant association between PC1 and adjusted PMD $(P=0.004)$. Comparing the distributions of $P C 1$ values between women with high and low adjusted PMD, we found that women with low PC1 values were over-represented in the high adjusted PMD group and women with high PC1 values were over-represented in the low adjusted PMD group (Figure 2). Using transformed values of PC1, with 0 representing the least amount of Ashkenazi Jewish ancestry as measured by PCA and 1 representing the greatest, having a PC1 value of 1 corresponded to an odds ratio (OR) of 2.0 for having high adjusted PMD. To adjust for the nonlinear relationship between BMI and PMD, we re-adjusted for BMI by quartiles (Table 2) and by deciles (Table S3 in Additional File 1) in multivariate analysis. The multivariate adjusted OR for the association of PC1 and adjusted PMD after adjusting for BMI by quartiles is 2.2 (95\% CI $=1.4$ to 3.6$)$. The same OR after adjusting for BMI by deciles is $2.2(95 \% \mathrm{CI}=1.3$ to 3.6$)$. We also analyzed our data by clustering women into subgroups based on the PCA results (Figure 1). The group of women that clustered with Ashkenazi Jews (Group 4) had an OR of $1.60(P=0.01$; Table S4 in Additional File 1$)$ of having high adjusted PMD compared with the group of women who clustered Northern Europeans (Group 1).

The seventh PC was also associated with adjusted PMD $(P=0.03)$, although we were unable to identify a correlation with an ancestral population and the seventh PC. The third PC (which corresponded to the second PC in the analysis with the ancestral populations and separated Northern versus Southern European ancestry) did not correlate with adjusted PMD $(P=0.3)$. Table S5 in Additional File 1 presents the correlation of each of the first 10 PCs with adjusted PMD.

Adjusting for the known epidemiologic and mammographic characteristics of the women in our sample did not attenuate the association between Ashkenazi Jewish ancestry and high adjusted PMD (Table 2). The OR for a woman with the most Ashkenazi Jewish ancestry, as defined by PCA, having high adjusted PMD versus low adjusted PMD remained approximately 2 . We adjusted for two additional variables outside the model shown in Table 2: breast volume and family history of breast cancer in a first-degree relative. Adjusting for the association between PC1 and breast volume moderately increased the significance of the association between PC1 and adjusted PMD (OR $=2.26$, $95 \% \mathrm{CI}=1.41$ to $3.62, P=0.001)$. Adjusting for family history of breast cancer did not attenuate the association (OR $=1.98,95 \% \mathrm{CI}=1.25$ to $3.14, P=0.004)$.

We performed additional analyses on individuals whose genetics suggested partial Ashkenazi Jewish ancestry to determine whether partial Ashkenazi Jewish ancestry was also associated with increased adjusted PMD. We examined the individuals who fell between

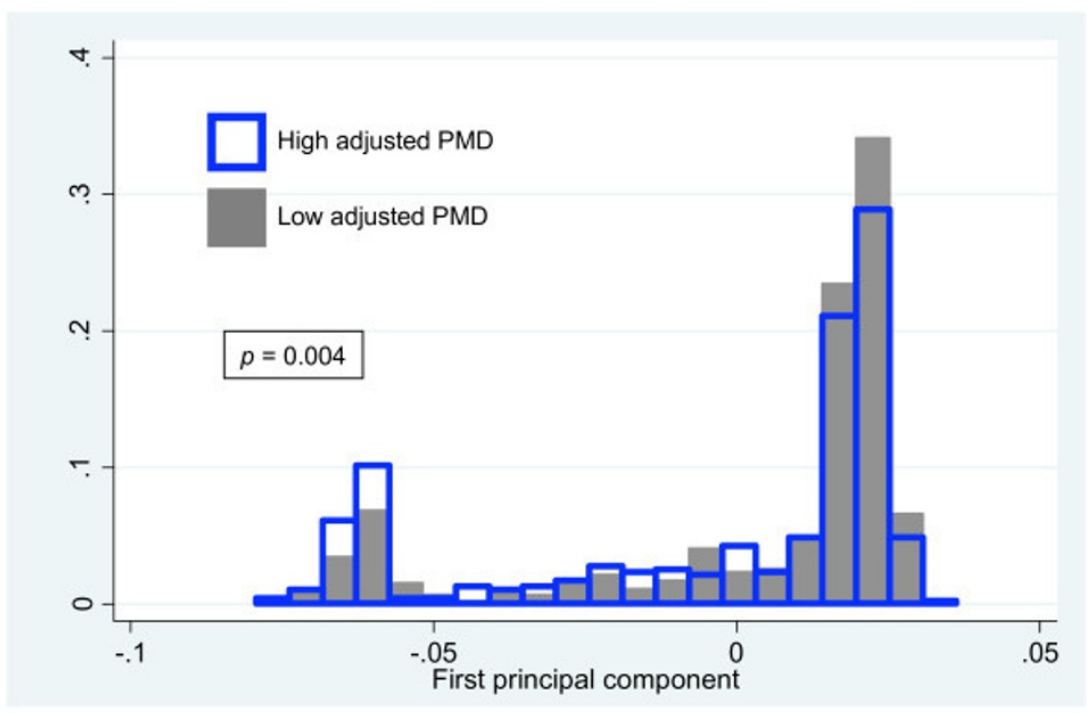

Figure 2 Position along the first principal component correlates with risk of high/low adjusted percent mammographic density. $P$ value of association between the first principal component and percent mammographic density (PMD) obtained using the Wilcoxon rank-sum test. 
Table 2 Multivariate regression of baseline characteristics and the first principal component with adjusted percent mammographic density

\begin{tabular}{|c|c|c|c|c|}
\hline & \multicolumn{2}{|l|}{ Univariate analyses } & \multicolumn{2}{|l|}{ Multivariate analysis } \\
\hline & Odds ratio (95\% confidence interval) & $P$ value & Odds ratio ( $95 \%$ confidence interval) & $P$ value \\
\hline First principal component & $2.00(1.26$ to 3.17$)$ & 0.003 & $2.22(1.36$ to 3.65$)$ & 0.002 \\
\hline \multicolumn{5}{|l|}{ Body mass index } \\
\hline First quartile $\left(<21 \mathrm{~kg} / \mathrm{m}^{2}\right)$ & Reference & & Reference & \\
\hline Second quartile (21 to $23 \mathrm{~kg} / \mathrm{m}^{2}$ ) & $0.41(0.28$ to 0.59$)$ & $<0.001$ & $0.38(0.26$ to 0.57$)$ & $<0.001$ \\
\hline Third quartile (23 to $26 \mathrm{~kg} / \mathrm{m}^{2}$ ) & $0.33(0.23$ to 0.49$)$ & $<0.001$ & $0.31(0.21$ to 0.46$)$ & $<0.001$ \\
\hline Fourth quartile $\left(>26 \mathrm{~kg} / \mathrm{m}^{2}\right)$ & $0.44(0.30$ to 0.63$)$ & $<0.001$ & $0.48(0.32$ to 0.71$)$ & $<0.001$ \\
\hline \multicolumn{5}{|l|}{ Age at first live birth } \\
\hline$<30$ years & Reference & & Reference & \\
\hline$\geq 30$ years or nulliparous & 1.27 (0.93 to 1.72$)$ & 0.1 & $1.13(0.80$ to 1.59$)$ & 0.5 \\
\hline \multicolumn{5}{|l|}{ Menopausal status } \\
\hline Premenopausal & Reference & & Reference & \\
\hline Postmenopausal & 0.67 (0.50 to 0.90$)$ & 0.009 & 0.67 (0.49 to 0.92$)$ & 0.01 \\
\hline Postmenopausal on hormone therapy & $0.72(0.49$ to 1.06$)$ & 0.1 & 0.74 (0.49 to 1.10$)$ & 0.1 \\
\hline
\end{tabular}

Odds ratios are for likelihood of having high adjusted percent mammographic density compared with low adjusted percent mammographic density. Univariate and multivariate $P$ values are calculated using chi-squared tests.

Group 1 (Northern European ancestry) and Group 4 (Ashkenazi Jewish ancestry) on PC1 (Figure 1). The second $\mathrm{PC}$ with the ancestral populations included divided this middle group into individuals who clustered with known Southern European groups (Group 2) and individuals who did not (Group 3). The IBD pattern in individuals in Group 3 supported our hypothesis that this group reflected an admixture between people of Ashkenazi Jewish ancestry and European ancestry, with Group 3 having higher within-group IBD than Group 2 as well as higher between-group IBD with Group 4 than did Group 2 (Table S6 in Additional File 1).

We compared the probability of having high adjusted PMD between the group with mixed Ashkenazi Jewish ancestry (Group 3) and the group with Southern European ancestry (Group 2). We adjusted this analysis for PC1 since women in Group 3 had slightly lower values on PC1 than did Group 2 (-0.02 vs. -0.01; $P=0.0007$ ). We found significantly higher probability of high adjusted PMD among Group 3 compared with Group 2 $(\mathrm{OR}=2.10 ; 95 \% \mathrm{CI}=1.05$ to 4.21$)$. This finding suggests that having partial Ashkenazi Jewish ancestry may contribute to an increased risk of having high adjusted PMD.

\section{Discussion}

We performed an analysis of genetic ancestry and ageadjusted and BMI-adjusted PMD, a strong risk factor for breast cancer. We found that the highest value of Ashkenazi Jewish ancestry, as identified by PCA, was associated with a twofold greater risk of having an adjusted PMD in the top quintile. When we analyzed women by clusters of ancestry, women who clustered with Ashkenazi Jews had a 1.6-fold greater likelihood of having higher adjusted PMD compared with women who clustered with Northern Europeans. This association was independent of total breast volume, parity, menopausal status, and postmenopausal hormone therapy. In addition, women who are likely to have partial Ashkenazi Jewish ancestry by PCA and IBD analysis also had higher adjusted PMD.

The identification of an ethnic group with higher adjusted PMD has significant implications for strategies to identify the genetic basis of this trait. Ashkenazi Jews have probably undergone a population bottleneck followed by rapid expansion, consistent with being a founder population $[41,42]$. Founder populations are more likely to have unique variants that are otherwise absent or exceptionally rare in other populations [43-46]. Since a genome-wide association study has only identified variants that account for $<1 \%$ of the variance in adjusted PMD [30], but adjusted PMD is estimated to be approximately $60 \%$ heritable [24-27], the vast majority of heritability for adjusted PMD remains unexplained. Our finding suggests that women of Ashkenazi Jewish ancestry may have unique genetic variant(s) or higher frequencies of variants that predispose to higher adjusted PMD.

Although a genetic effect is a plausible explanation for the higher adjusted PMD in Ashkenazi Jewish women, we cannot rule out unmeasured nongenetic confounders. We adjusted for some factors known to be associated with PMD including age at parity, menopausal status, and use of postmenopausal hormone therapy. However, we did not adjust for other factors such as age at menarche or number of children. The finding that women of partial Ashkenazi Jewish ancestry also have higher adjusted PMD supports a genetic basis for the increased adjusted PMD in 
Ashkenazi Jews, although it is also possible that women of mixed Ashkenazi Jewish descent are exposed to the same environmental factors as women of Ashkenazi Jewish descent.

One limitation of our study is that we did not have information about whether these women self-identified as Ashkenazi Jews. However, other genetic studies with selfidentification information have identified Ashkenazi Jews as a cluster among US Caucasians [47,48]. Furthermore, individuals who self-identify as having partial Ashkenazi Jewish ancestry can also been identified by PCA [49].

Another limitation of our study was that our analysis depended on both the measurement of PMD using the SXA approach and on a sampling scheme that sampled the top and bottom quintiles. The SXA measurement of PMD is known to have high reproducibility [6] and has been associated with breast cancer risk [5]. In addition, we found an association between high adjusted PMD and family history of breast cancer, as has previously been observed with qualitative measures of breast density $[50,51]$. However, it is possible that the association between adjusted PMD and genetic ancestry is only apparent when measuring PMD using SXA and is an artifact of that method; additional studies of PMD and ancestry will be necessary to confirm that the association remains when different methods are used to measure PMD. In addition, our analysis sampled the top and bottom quintiles of ageadjusted and BMI-adjusted PMD. The association between genetic ancestry and this trait may be due to a differential effect of age or BMI on PMD in Ashkenazi Jews compared with other Caucasians. We calculated the BMI using selfreported height and weight, which can underestimate high BMI values and overestimate low BMI values [52].

Finally, our adjustment for the effect of BMI on PMD as part of the sampling did not completely eliminate the association between PMD and BMI. We noted an association between BMI and adjusted PMD, even after we had adjusted PMD for BMI. We believe this association was due to a nonlinear relationship between BMI and PMD, especially at higher BMIs. We therefore stratified by BMI quartile and by decile and re-adjusted for BMI in the multivariate analysis using these categories, and did not detect any attenuation of the main association between ancestry and adjusted PMD. Future studies of PMD may benefit from adjusting for BMI initially by categories rather than using a linear regression to avoid having to adjust twice.

The Ashkenazi Jewish population has been reported to have higher rates of breast cancer compared with other Caucasian populations [53], which may be at least partially explained by its high prevalence of two founder mutations in BRCA 1 and one founder mutation in BRCA2 [54]. However, the increased prevalence of BRCA1 and BRCA2 germline mutation carriers is unlikely to explain the association of adjusted PMD with
Ashkenazi Jewish ancestry, as two studies have demonstrated no association between BRCA1 or BRCA2 mutation status and PMD $[55,56]$. Based on our data we cannot determine whether increased PMD in Ashkenazi Jewish women is associated with an increased risk of breast cancer independent of BRCA1 and BRCA2. Ashkenazi Jews may have higher PMD because of genetic or environmental factors that increase PMD but have no impact on breast cancer risk. Alternatively, higher PMD in Ashkenazi Jews may result from previously unknown genetic risk factors for breast cancer development.

\section{Conclusions}

In summary, women of Ashkenazi Jewish ancestry are more likely to have high age-adjusted and BMI-adjusted PMD. Environmental risk factors, genetic variation, or both may explain this finding. Ashkenazi Jews are a founder population with substantially higher IBD compared with other populations. One or more genetic variant(s) unique to this population may therefore increase PMD. Further research is needed to uncover potential genetic determinants underlying the higher adjusted PMD in this group, which in turn may shed new light on the biologic mechanisms of PMD.

\section{Additional material}

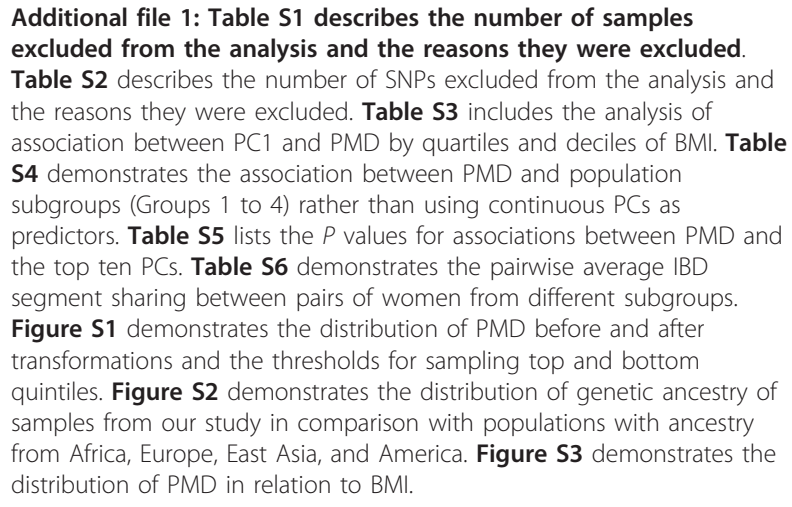

\section{Abbreviations}

BMI: body mass index; Cl: confidence interval; IBD: identity by descent; OR: odds ratio; PC: principal component; PC1: first principal component; PCA: principal components analysis; PMD: percent mammographic density; SNP: single nucleotide polymorphism; SXA: single X-ray absorptiometry.

\section{Competing interests}

The authors declare that they have no competing interests.

\section{Authors' contributions}

JLC performed the statistical analysis and data interpretation and drafted the manuscript. KK obtained funding, contributed to data acquisition and interpretation of the results, and made critical reviews to the manuscript. JAS performed the PMD measurements and made critical reviews to the manuscript. SRC obtained funding, contributed to data acquisition and made critical reviews to the manuscript. DH and SH made contributions to 
the bioinformatics analysis and made critical reviews to the manuscript. EZ designed the study, obtained funding, provided interpretation of the data and helped to draft the manuscript. All authors read and approved the manuscript for publication.

\section{Acknowledgements}

The authors are grateful to Alice Larocca and Viktoriya Kopvak for assistance with database management and for retrieving the samples. They are grateful to Noah Rosenberg, Doron Behar, and Karl Skorecki for helpful discussions about the results of the analysis. Genotyping was supported by the National Institutes of Health HHSN268200782096C and HHSN2682011000111, and was completed at the Johns Hopkins University Center for Inherited Disease Research. Support for analysis was provided by R01CA120120 and K24169004 to EZ. Support for sample collection was provided by the DaCosta International Fund for Prevention of Breast Cancer, the Eli Lilly Foundation, and the California Pacific Medical Center CRCLE Program. The San Francisco Mammography Registry is supported by an NCl-funded Breast Cancer Surveillance Consortium cooperative agreement (U01CA63740).

\section{Authors' details}

'Department of Medicine, Division of General Internal Medicine, Institute for Human Genetics, Helen Diller Family Comprehensive Cancer Center, University of California, $14503^{\text {rd }}$ Street, San Francisco, CA 94143, USA. ${ }^{2}$ Department of Medicine and Department of Epidemiology and Biostatistics, University of California, San Francisco, San Francisco Veterans Affairs Medical Center, General Internal Medicine Section 111A1, 4150 Clement Street, San Francisco, CA 94121, USA. ${ }^{3}$ Department of Radiology and Biomedical Imaging, University of California, San Francisco, MRSC AC122, 1 Irving Street (Box 0628), San Francisco, CA 94143-0628, USA. ${ }^{4}$ San Francisco Coordinating Center, California Pacific Medical Center Research Institute, 185 Berry St., Lobby 5, Suite 5700, San Francisco, CA, 94107, USA.

Received: 26 November 2012 Revised: 23 January 2013 Accepted: 13 May 2013 Published: 13 May 2013

\section{References}

1. Boyd NF, Byng JW, Jong RA, Fishell EK, Little LE, Miller AB, Lockwood GA, Tritchler DL, Yaffe MJ: Quantitative classification of mammographic densities and breast cancer risk: results from the Canadian National Breast Screening Study. J Natl Cancer Inst 1995, 87:670-675.

2. Byrne C, Schairer C, Wolfe J, Parekh N, Salane M, Brinton LA, Hoover R, Haile R: Mammographic features and breast cancer risk: effects with time, age, and menopause status. J Natl Cancer Inst 1995, 87:1622-1629.

3. Boyd NF, Lockwood GA, Byng JW, Tritchler DL, Yaffe MJ: Mammographic densities and breast cancer risk. Cancer Epidemiol Biomarkers Prev 1998, 7:1133-1144.

4. Shepherd JA, Herve L, Landau J, Fan B, Kerlikowske K, Cummings SR: Novel use of single X-ray absorptiometry for measuring breast density. Technol Cancer Res Treat 2005, 4:173-182.

5. Shepherd JA, Kerlikowske K, Ma L, Duewer F, Fan B, Wang J, Malkov S, Vittinghoff $E_{1}$ Cummings SR: Volume of mammographic density and risk of breast cancer. Cancer Epidemiol Biomarkers Prev 2011, 20:1473-1482.

6. Malkov S, Wang J, Kerlikowske K, Cummings SR, Shepherd JA: Single X-ray absorptiometry method for the quantitative mammographic measure of fibroglandular tissue volume. Med Phys 2009, 36:5525-5536.

7. Glide-Hurst CK, Duric N, Littrup P: Volumetric breast density evaluation from ultrasound tomography images. Med Phys 2008, 35:3988-3997.

8. Jeffreys M, Warren R, Highnam R, Davey Smith G: Breast cancer risk factors and a novel measure of volumetric breast density: cross-sectional study. Br J Cancer 2008, 98:210-216.

9. Mawdsley GE, Tyson AH, Peressotti CL, Jong RA, Yaffe MJ: Accurate estimation of compressed breast thickness in mammography. Med Phys 2009, 36:577-586.

10. Alonzo-Proulx O, Packard N, Boone JM, Al-Mayah A, Brock KK, Shen SZ, Yaffe MJ: Validation of a method for measuring the volumetric breast density from digital mammograms. Phys Med Biol 2010, 55:3027-3044.

11. Lokate M, Kallenberg MG, Karssemeijer N, Van den Bosch MA, Peeters PH, Van Gils CH: Volumetric breast density from full-field digital mammograms and its association with breast cancer risk factors: a comparison with a threshold method. Cancer Epidemiol Biomarkers Prev 2010, 19:3096-3105.
12. Ding $H$, Molloi S: Quantification of breast density with spectral mammography based on a scanned multi-slit photon-counting detector: a feasibility study. Phys Med Biol 2012, 57:4719-4738.

13. Wu X, Yan A, Liu H: X-ray phase-shifts-based method of volumetric breast density measurement. Med Phys 2012, 39:4239-4244.

14. Hong CC, Thompson HJ, Jiang C, Hammond GL, Tritchler D, Yaffe M, Boyd NF: Val158Met polymorphism in catechol-O-methyltransferase gene associated with risk factors for breast cancer. Cancer Epidemiol Biomarkers Prev 2003, 12:838-847.

15. McCormack VA, dos Santos Silva I: Breast density and parenchymal patterns as markers of breast cancer risk: a meta-analysis. Cancer Epidemiol Biomarkers Prev 2006, 15:1159-1169.

16. Yaffe MJ, Boyd NF, Byng JW, Jong RA, Fishell E, Lockwood GA, Little LE, Tritchler DL: Breast cancer risk and measured mammographic density. Eur J Cancer Prev 1998, 7(Suppl 1):S47-S55.

17. Vachon CM, Sellers TA, Vierkant RA, Wu FF, Brandt KR: Case-control study of increased mammographic breast density response to hormone replacement therapy. Cancer Epidemiol Biomarkers Prev 2002, 11:1382-1388.

18. Ursin $G, M a ~ H, W u A H$, Bernstein $L$, Salane M, Parisky YR, Astrahan M, Siozon CC, Pike MC: Mammographic density and breast cancer in three ethnic groups. Cancer Epidemiol Biomarkers Prev 2003, 12:332-338.

19. Ziv E, Tice J, Smith-Bindman R, Shepherd J, Cummings S, Kerlikowske K: Mammographic density and estrogen receptor status of breast cancer. Cancer Epidemiol Biomarkers Prev 2004, 13:2090-2095.

20. Vachon CM, van Gils $C H$, Sellers TA, Ghosh K, Pruthi S, Brandt KR, Pankratz VS: Mammographic density, breast cancer risk and risk prediction. Breast Cancer Res 2007, 9:217.

21. Vachon CM, Kuni CC, Anderson K, Anderson VE, Sellers TA: Association of mammographically defined percent breast density with epidemiologic risk factors for breast cancer (United States). Cancer Causes Control 2000, 11:653-662.

22. Chen J, Pee D, Ayyagari R, Graubard B, Schairer C, Byrne C, Benichou J, Gail MH: Projecting absolute invasive breast cancer risk in white women with a model that includes mammographic density. I Natl Cancer Inst 2006, 98:1215-1226.

23. Tice JA, Cummings SR, Ziv E, Kerlikowske K: Mammographic breast density and the gail model for breast cancer risk prediction in a screening population. Breast Cancer Res Treat 2005, 94:115-122.

24. Boyd NF, Dite GS, Stone J, Gunasekara A, English DR, McCredie MR, Giles GG, Tritchler D, Chiarelli A, Yaffe MJ, Hopper JL: Heritability of mammographic density, a risk factor for breast cancer. N Engl J Med 2002, 347:886-894.

25. Stone J, Dite GS, Gunasekara A, English DR, McCredie MR, Giles GG, Cawson JN, Hegele RA, Chiarelli AM, Yaffe MJ, Boyd NF, Hopper JL: The heritability of mammographically dense and nondense breast tissue. Cancer Epidemiol Biomarkers Prev 2006, 15:612-617.

26. Sung J, Song YM, Stone J, Lee K, Jeong JI, Kim SS: Genetic influences on mammographic density in Korean twin and family: the Healthy Twin study. Breast Cancer Res Treat 2010, 124:467-474.

27. Ursin G, Lillie EO, Lee E, Cockburn M, Schork NJ, Cozen W, Parisky YR, Hamilton AS, Astrahan MA, Mack T: The relative importance of genetics and environment on mammographic density. Cancer Epidemiol Biomarkers Prev 2009, 18:102-112.

28. Vachon CM, Scott CG, Fasching PA, Hall P, Tamimi RM, Li J, Stone J, Apicella C, Odefrey F, Gierach GL, Jud SM, Heusinger K, Beckmann MW, Pollan M, Fernández-Navarro P, Gonzalez-Neira A, Benitez J, van Gils CH, Lokate M, Onland-Moret NC, Peeters PH, Brown J, Leyland J, Varghese JS, Easton DF, Thompson DJ, Luben RN, Warren RM, Wareham NJ, et al: Common breast cancer susceptibility variants in LSP1 and RAD51L1 are associated with mammographic density measures that predict breast cancer risk. Cancer Epidemiol Biomarkers Prev 2012, 21:1156-1166.

29. Greenwood CM, Paterson AD, Linton L, Andrulis IL, Apicella C, Dimitromanolakis A, Kriukov V, Martin L, Salleh A, Samiltchuk E, Parekh RV, Southey MC, John EM, Hopper JL, Boyd NF, Rommens JM: A genome-wide linkage study of mammographic density, a risk factor for breast cancer. Breast Cancer Res 2011, 13:R132.

30. Lindstrom S, Vachon CM, Li J, Varghese J, Thompson D, Warren R, Brown J, Leyland J, Audley T, Wareham NJ, Loos RJ, Paterson AD, Rommens J, Waggott D, Martin L, Scott CG, Pankratz VS, Hankinson SE, Hazra A, Hunter DJ, Hopper JL, Southey MC, Chanock SJ, Silva Idos S, Liu J, Eriksson L, Couch FJ, Stone J, Apicella C, Czene K, Kraft P, Hall P, Easton DF, 
Boyd NF, Tamimi RM: Common variants in ZNF365 are associated with both mammographic density and breast cancer risk. Nat Genet 2011, 43:185-187.

31. Stevens KN, Lindstrom S, Scott CG, Thompson D, Sellers TA, Wang $X$, Wang A, Atkinson E, Rider DN, Eckel-Passow JE, Varghese JS, Audley T, Brown J, Leyland J, Luben RN, Warren RM, Loos RJ, Wareham NJ, Li J, Hall P, Liu J, Eriksson L, Czene K, Olson JE, Pankratz VS, Fredericksen Z, Diasio RB, Lee AM, Heit JA, DeAndrade M, et al: Identification of a novel percent mammographic density locus at 12q24. Hum Mol Genet 2012 21:3299-3305.

32. Vachon CM, Sellers TA, Carlson EE, Cunningham JM, Hilker CA, Smalley RL, Schaid DJ, Kelemen LE, Couch FJ, Pankratz VS: Strong evidence of a genetic determinant for mammographic density, a major risk factor for breast cancer. Cancer Res 2007, 67:8412-8418.

33. Varghese JS, Thompson DJ, Michailidou K, Lindstrom S, Turnbull C, Brown J, Leyland J, Warren RM, Luben RN, Loos RJ, Wareham NJ, Rommens J, Paterson AD, Martin LJ, Vachon CM, Scott CG, Atkinson EJ, Couch FJ, Apicella C, Southey MC, Stone J, Li J, Eriksson L, Czene K, Boyd NF, Hall P, Hopper JL, Tamimi RM, MODE Consortium, Rahman N, Easton DF: Mammographic breast density and breast cancer: evidence of a shared genetic basis. Cancer Res 2012, 72:1478-1484.

34. Price AL, Patterson NJ, Plenge RM, Weinblatt ME, Shadick NA, Reich D: Principal components analysis corrects for stratification in genome-wide association studies. Nat Genet 2006, 38:904-909.

35. Behar DM, Yunusbayev B, Metspalu M, Metspalu E, Rosset S, Parik J, Rootsi S, Chaubey G, Kutuev I, Yudkovsky G, Khusnutdinova EK, Balanovsky O, Semino O, Pereira L, Comas D, Gurwitz D, Bonne-Tamir B, Parfitt T, Hammer MF, Skorecki K, Villems R: The genome-wide structure of the Jewish people. Nature 2010, 466:238-242.

36. Li JZ, Absher DM, Tang H, Southwick AM, Casto AM, Ramachandran S, Cann HM, Barsh GS, Feldman M, Cavalli-Sforza LL, Myers RM: Worldwide human relationships inferred from genome-wide patterns of variation. Science 2008, 319:1100-1104.

37. Gusev A, Lowe JK, Stoffel M, Daly MJ, Altshuler D, Breslow JL, Friedman JM, Pe'er I: Whole population, genome-wide mapping of hidden relatedness. Genome Res 2009, 19:318-326.

38. Browning BL, Browning SR: A unified approach to genotype imputation and haplotype-phase inference for large data sets of trios and unrelated individuals. Am J Hum Genet 2009, 84:210-223.

39. Atzmon G, Hao L, Pe'er I, Velez C, Pearlman A, Palamara PF, Morrow B, Friedman E, Oddoux C, Burns E, Ostrer H: Abraham's children in the genome era: major Jewish diaspora populations comprise distinct genetic clusters with shared Middle Eastern Ancestry. Am J Hum Genet 2010, 86:850-859.

40. Gusev A, Palamara PF, Aponte G, Zhuang Z, Darvasi A, Gregersen P, Pe'er I: The architecture of long-range haplotypes shared within and across populations. Mol Biol Evol 2012, 29:473-486.

41. Risch N, Tang H, Katzenstein H, Ekstein J: Geographic distribution of disease mutations in the Ashkenazi Jewish population supports genetic drift over selection. Am J Hum Genet 2003, 72:812-822.

42. Risch N, de Leon D, Ozelius L, Kramer P, Almasy L, Singer B, Fahn S, Breakefield X, Bressman S: Genetic analysis of idiopathic torsion dystonia in Ashkenazi Jews and their recent descent from a small founder population. Nat Genet 1995, 9:152-159.

43. Laberge AM, Michaud J, Richter A, Lemyre E, Lambert M, Brais B, Mitchell GA: Population history and its impact on medical genetics in Quebec. Clin Genet 2005, 68:287-301.

44. Rahman P, Jones A, Curtis J, Bartlett S, Peddle L, Fernandez BA, Freimer NB: The Newfoundland population: a unique resource for genetic investigation of complex diseases. Hum Mol Genet 2003, 12(Spec No 2): R167-R172.

45. Chapman NH, Thompson EA: Linkage disequilibrium mapping: the role of population history, size, and structure. Adv Genet 2001, 42:413-437.

46. Peltonen $\mathrm{L}$ : Molecular background of the Finnish disease heritage. Ann Med 1997, 29:553-556.

47. Price AL, Butler J, Patterson N, Capelli C, Pascali VL, Scarnicci F, RuizLinares A, Groop L, Saetta AA, Korkolopoulou P, Seligsohn U, Waliszewska A, Schirmer C, Ardlie K, Ramos A, Nemesh J, Arbeitman L, Goldstein DB, Reich D, Hirschhorn JN: Discerning the ancestry of European Americans in genetic association studies. PLoS Genet 2008, 4:e236.
48. Tian C, Plenge RM, Ransom M, Lee A, Villoslada P, Selmi C, Klareskog L, Pulver AE, Qi L, Gregersen PK, Seldin MF: Analysis and application of European genetic substructure using $300 \mathrm{~K}$ SNP information. PLoS Genet 2008, 4:e4.

49. Need AC, Kasperaviciute D, Cirulli ET, Goldstein DB: A genome-wide genetic signature of Jewish ancestry perfectly separates individuals with and without full Jewish ancestry in a large random sample of European Americans. Genome Biol 2009, 10:R7.

50. Ziv E, Shepherd J, Smith-Bindman R, Kerlikowske K: Mammographic breast density and family history of breast cancer. J Natl Cancer Inst 2003, 95:556-558.

51. Crest $A B$, Aiello EJ, Anderson ML, Buist DS: Varying levels of family history of breast cancer in relation to mammographic breast density (United States). Cancer Causes Control 2006, 17:843-850.

52. Stommel M, Schoenborn CA: Accuracy and usefulness of BMI measures based on self-reported weight and height: findings from the NHANES \& NHIS 2001-2006. BMC Public Health 2009, 9:421.

53. Newill VA: Distribution of cancer mortality among etimic subgroups of the white population of New York City, 1953-58. J Natl Cancer Inst 1961, 26:405-417.

54. Levy-Lahad E, Catane R, Eisenberg S, Kaufman B, Hornreich G, Lishinsky E, Shohat M, Weber BL, Beller U, Lahad A, Halle D: Founder BRCA1 and BRCA2 mutations in Ashkenazi Jews in Israel: frequency and differential penetrance in ovarian cancer and in breast-ovarian cancer families. Am J Hum Genet 1997, 60:1059-1067.

55. Gierach GL, Loud JT, Chow CK, Prindiville SA, Eng-Wong J, Soballe PW, Giambartolomei C, Mai PL, Galbo CE, Nichols K, Calzone KA, Vachon C, Gail MH, Greene MH: Mammographic density does not differ between unaffected BRCA1/2 mutation carriers and women at low-to-average risk of breast cancer. Breast Cancer Res Treat 2010, 123:245-255.

56. Mitchell G, Antoniou AC, Warren R, Peock S, Brown J, Davies R, Mattison J, Cook M, Warsi I, Evans DG, Eccles D, Douglas F, Paterson J, Hodgson S, Izatt L, Cole T, Burgess L, Eeles R, Easton DF: Mammographic density and breast cancer risk in BRCA1 and BRCA2 mutation carriers. Cancer Res 2006, 66:1866-1872.

doi:10.1186/bcr3424

Cite this article as: Caswell et al:: High mammographic density in women of Ashkenazi Jewish descent. Breast Cancer Research 2013 15:R40.

\section{Submit your next manuscript to BioMed Central and take full advantage of:}

- Convenient online submission

- Thorough peer review

- No space constraints or color figure charges

- Immediate publication on acceptance

- Inclusion in PubMed, CAS, Scopus and Google Scholar

- Research which is freely available for redistribution

Submit your manuscript at www.biomedcentral.com/submit
C Biomed Central 